\title{
AC 2011-2301: UNIT OPERATIONS LAB BAZAAR: ASSESSMENT OF MINIATURE INDUSTRIAL EQUIPMENT
}

\author{
Laura Coon, Washington State University
}

A recent graduate of WSU, Laura aspires to find learning and understanding in everything she does. Born and raised in Seattle, WA Laura is 22 and loving every minute of life as a chemical engineer. During her education at WSU she worked under Dr. Bernard Van Wie in heat transfer and fluid flow education research, specifically assessing the desktop learning module double pipe and shell and tube cartridges.

\section{Mr. Paul B Golter, Washington State University}

Paul B. Golter obtained an MS from Washington State University and recently defended his PhD degree and is currently the Laboratory Supervisor in the Voiland School of School of Chemical Engineering and Bio-engineering at WSU. He is married with three children.509-338-5724.

\section{Mr. Derek Allen Cline}

Ashley Ater Kranov, Washington State University

Dr. Ater Kranov is Director of Educational Innovation and Assessment for the College of Engineering and Architecture at Washington State University, USA. She is affiliated assistant professor in the School of Electrical Engineering and Computer Science where she co-teaches the 2-semester senior design capstone sequence.

The paper describing her collaborative work with faculty in the WSU College of Engineering and Architecture, "A Direct Method for Teaching and Assessing the ABET Professional Skills in Engineering Programs", won the 2008 ASEE Best Conference Paper Award. She has served as evaluator on a number of multi-institutional, interdisciplinary NSF sponsored grants. She is principal investigator on a NSF Research and Evaluation on Education in Science and Engineering project called "A Direct Method for Teaching and Measuring Engineering Professional Skills: A Validity Study."

\section{David B. Thiessen, Washington State University}

David B.Thiessen received his $\mathrm{PhD}$ in Chemical Engineering from the University of Colorado in 1992 and has been at Washington State University since 1994. His research interests include fluid physics, acoustics, and engineering education.

\section{Bernard J. Van Wie, Washington State University}

Prof. Bernard J. Van Wie did his B.S., M.S. and Ph.D. and postdoctoral work at the University of Oklahoma where he also taught as a Visiting Lecturer. He has been on the Washington State University faculty for 28 years and over the past 14 years has focused strongly on innovative pedagogy along with his technical research in biotechnology. His recent Fulbright Exchange to Nigeria set the stage for receipt of the Marian Smith Award given annually to the most innovative teacher at WSU. (509) 335-4103 (Off); (509) 335-4806 (Fax); bvanwie @ che.wsu.edu. 


\title{
Unit Operations Lab Bazaar: Assessment of Miniature Industrial Equipment
}

\begin{abstract}
There is a need for lower cost undergraduate Unit Operations equipment to meet needs at budget constrained colleges and universities, and industrial technology programs. There is a further need to reduce the space in which equipment is housed and to design flexible systems that can perform more than one task, especially for emerging departments in countries where departments must rent space from their own universities. Washington State University has developed a way to meet these needs by providing miniaturized low-cost industrial equipment on the scale order of a dollar bill and in the form of interchangeable cartridges. Clear plastic casing allows students to directly observe the fluid flow arrangement and meaning behind the various pitches, tubes sizes, spacings, turns and basic geometry that encompass typical equipment and are used in mathematical modeling of such systems. The cartridges snap into a base module small enough to fit on a desk that contains fluid reservoirs, flow meters and temperature and pressure readouts.

In this paper, the traditional shell and tube heat exchanger is examined. A challenge with miniaturization is how flow profiles will affect pressure drops and heat transfer coefficients. Reliable correlations exist for pilot and industrial scale equipment; however, it remains to be shown for smaller geometries, if analyses will be impacted by issues such as non-fully developed flow profiles, or heat and friction losses occurring because of un-insulated surfaces and large surface area to volume ratios. Herein, is presented an assessment of a very small scale shell and tube heat exchanger. It is shown that pressure drop correlations are in reasonable agreement with measured values; and that heat transfer correlations offer reasonable agreement with experimental values, within the expected $\pm 25-35 \%$.
\end{abstract}

\section{Introduction}

An education in engineering is more than the assimilation of facts, it is the application of those facts and the ability to apply knowledge to novel problems as they arise. Educators are continuously thinking of new and innovative ways to accomplish this, producing competent, knowledgeable engineers. Advances have been made to this end ${ }^{1,2,3,4,5,6}$, in applying Cooperative, Hands-on, Active and Problem based Learning, more commonly referred to as the CHAPL pedagogy, ${ }^{7}$ in the form of both teaching methods, applied experiments, and equipment. It has been shown that when physical teaching aids and real life examples are employed in education, the student more often thinks outside the scope of the course and retains the essential knowledge for later application ${ }^{8,9}$ which is why access to a Unit Operations Laboratory is essential to a well rounded education in engineering. In this paper we will be focusing specifically on the advances made in heat transfer and fluid flow education in the form of miniaturized industrial equipment.

Even though the importance of hands on learning and laboratory experience is accepted by many educational institutions ${ }^{8,9}$, not all have the resources available to furnish a laboratory with educational equipment either on industrial, educational or model scale. Desktop Learning Modules (DLMs) developed at Washington State University are aimed at overcoming the special and financial restraints faced by many institutions. Just over one cubic foot and powered by an 
enclosed lead-acid battery, the DLMs are portable heat transfer and fluid flow units with interchangeable cartridges for different heat exchanger and fluid flow models. One DLM contains two water reservoirs each attached to an $8.3 \mathrm{~W}$ DC centrifugal pump, rotameter, thermocouples at inlet and outlet fluid flow lines on the removable cartridges and differential pressure readout from each cartridge as necessary which are read on a small LCD screen, and recycle lines that can be applied or removed to create dynamic or static systems. The cartridges are small reproductions of heat transfer and/or fluid mechanics equipment that would be commonly found in industry. ${ }^{10}$

Within the advances in the accessibility of hands on learning, care needs to be taken to make sure that the educating tools being developed not only teach the concepts, but compare well with what students might encounter in industry. In this paper we assess the heat transfer capabilities of the shell and tube cartridge of a DLM. Specifically we target the assumption that miniaturizing a heat exchanger does not significantly affect the correlations designed by industry to model heat transfer and fluid flow in a heat exchanger. After completion of this analysis it is shown that the error associated with heat transfer correlations when applied to the miniaturized equipment found in the DLMs, specifically the shell and tube heat exchanger cartridge, is on par with the error associated with applying the same correlations to industrial scale equipment (error of \pm 20 - $30 \%$ on overall heat transfer coefficients while excluding extraneous data points) ${ }^{11}$ and within ranges tabulated in literature. ${ }^{12}$

\section{Theory and Experimental Calculations}

While chemical engineers are well acquainted with the theory and correlations developed for heat exchanger design we describe the exact methods used for calculations in the particular lab experiment at hand so there will be no confusion as to what was done. Experimentally, the amount of heat transferred in the exchanger may be calculated from the average values determined by energy balances for the shell and the tube sides of the exchanger.

$$
\begin{array}{ll}
Q_{\text {exp }, o}=\dot{m}_{s} * C p *\left|T_{\text {out }, s}-T_{\text {in, }, s}\right| & \text { Eq } 1 \\
Q_{\text {exp }, i}=\dot{m}_{t} * C p *\left|T_{\text {out }, t}-T_{\text {in }, t}\right| & \text { Eq } 2
\end{array}
$$

Validity of the experimental values for the two fluids may be checked by comparing the two values of $\mathrm{Q}$ - this adds validity to arguments that substantial amounts of heat are not lost to surrounding air through natural convection or through system connectors, and that the shell and tube side flow rates, and recorded temperatures have been properly determined.

An experimental overall heat transfer coefficient based on the inside area may be calculated from the heat transferred from the hot to the cold fluid:

$$
U_{i}=\frac{Q_{i}}{A_{i} * \Delta T_{l m}}
$$

The log mean temperature difference has its standard meaning: 


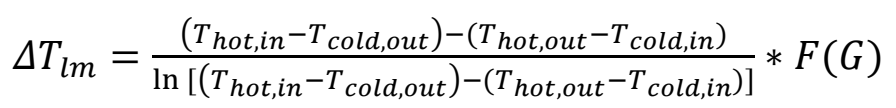

With the correction factor, $\mathrm{F}(\mathrm{G})$ for a 1 pass shell side and 2 pass tube side exchanger applied to the log mean temperature difference as described with the correction factor a function of the two parameters $\mathrm{R}$ and $\mathrm{S}$ as shown below. ${ }^{12}$

$$
\begin{gathered}
R=\frac{T_{\text {cold out }}-T_{\text {cold in }}}{T_{\text {hot out }}-T_{\text {hot in }}} \\
S=\frac{T_{\text {hot out }}-T_{\text {hot in }}}{T_{\text {cold out }}-T_{\text {hot in }}} \\
F_{G}=\frac{\sqrt{R^{2}+1} * \ln \left(\frac{1-S}{1-R * S}\right)}{(R-1) * \ln \left(\frac{2-S *\left(R+1-\sqrt{R^{2}+1}\right)}{2-S *\left(R+1-\sqrt{R^{2}+1}\right)}\right)}
\end{gathered}
$$

Using the modified shell and tube exchanger with thermocouples attached at the middle and either end of the tube bundle on both first and second tube passes, experimental individual heat transfer coefficients $h_{i}$ and $h_{o}$ can be derived using the following equations.

$$
\begin{aligned}
& h_{i}=\frac{Q_{i}}{A_{i} *\left(T_{\left.w_{\text {wall }, a v e}-T_{\text {bulk }, i}\right)}\right.} \\
& h_{o}=\frac{Q_{o}}{A_{o} *\left(T_{\text {wall } \left._{\text {ave }}-T_{\text {bulk }, o}\right)}\right.}
\end{aligned}
$$

The bulk temperature is taken as the arithmetic mean temperature of each respected side. The wall temperature is calculated by a weighted average of the thermocouple readouts. The current setup only allows for the collection of four of the six thermocouples in 30 second intervals. To compensate, the thermocouples recorded in a dataset are switched every few points so that the temperatures from the points on either side of a switch can be averaged to give a complete pseudo data point where all thermocouples are recorded.

\section{Correlated Heat Transfer Coefficients}

To check the heat exchanger against standard correlations, the heat transfer correlations developed for industrial scale equipment were applied to the DLMs. Correlations from McCabe et al. ${ }^{12}$ and Thomson ${ }^{13}$ are used to determine the shell side and tube side individual heat transfer coefficients as well as overall heat transfer coefficients. These are the same correlations commonly taught in fluid flow and heat transfer courses and used in industry to design and analyze heat exchangers.

Nusselt number correlation for the tube-side flow which, given our current system always resides in the laminar flow regime, varies in form depending on spatial orientation system and geometry, in our case horizontal flow in round tubes, and is a function of the Graetz number, which in turn is dependent on the Reynolds Number $(\mathrm{Re})$, Prandtl Number $(\operatorname{Pr})$, and aspect ratio D/L. ${ }^{13}$

$$
N u_{i}=3.66+\frac{0.085 * G z}{1+.047 * G z^{\cdot 67}}
$$


In calculating the Graetz number by the relation below, we use the tube inside diameter, length of one tube pass and Re and Pr based on the intrinsic tube side fluid properties, $C_{p}, \mu, \rho$, and $\mathrm{k}$ determined at the average bulk fluid temperature.

$$
G z=\pi * \operatorname{Re} * \operatorname{Pr} *\left(\frac{D_{i}}{L}\right) / 4
$$

Shell side Nusselt number is calculated with the Donahue equation for heat transfer to baffled tube banks which is noted to give conservatively low estimates when used in the calculation of $h_{o}$ at low Reynolds numbers such as is the case here. ${ }^{12}$

$$
N u_{o}=0.2 * R e^{0.6} * \operatorname{Pr}^{0.33} *{\frac{\mu}{\mu_{w}}}^{0.14}
$$

The shell side Reynolds number is based on the tube outside diameter and average mass velocity:

$$
R e=\frac{\left(D_{o} * G e\right)}{\mu_{t}}
$$

Where the average mass velocity in the shell, Ge, is as follows: ${ }^{12}$

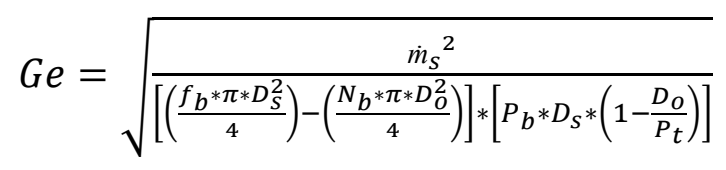

Once $\mathrm{Nu}$ values are determined for both the inside and outside streams the heat transfer coefficients $h_{i}$ and $h_{o}$ may be determined by multiplying through by the appropriate k/D.

$$
\begin{aligned}
& h_{i}=\frac{N u_{i} * k}{D_{i}} \\
& h_{o}=\frac{N u_{o} * k}{D_{o}}
\end{aligned}
$$

Because two shell and tube cartridges are used, only one of which has been modified with wall thermocouples, it is necessary to use an estimate for the wall temperature in the unmodified cartridge. By using the below equation, which is based on individual heat transfer coefficients, the calculation for the overall heat transfer coefficient becomes iterative. In two to three iterations, the calculated wall side temperature changes less than 0.1 degree Celsius between iterations and the present value is assumed sufficient for final overall heat transfer coefficient calculation. Taking into account that industrial heat exchangers are usually not equipped with wall side thermocouples, the wall side temperature equation is used in both data sets, with and without wall side thermocouple data, so that the correlated overall heat transfer produced is what would be calculated by users of an unmodified unit. These values may also be used for viscosity correction factors based on the wall temperature, though the temperature differences between the wall and the bulk are not extreme in the experiments analyzed in this paper and therefore the correction factor may be considered to have a value of unity. 


$$
T_{w}=T_{b u l k, h o t}-\frac{\Delta T / h_{i}}{\frac{1}{h_{i}}+\frac{D_{o} / D_{i}}{h_{o}}}
$$

The term for wall resistance included was found to be sufficiently small and therefore was ignored for purposes of calculating overall heat transfer coefficients. The equations for $U_{i}$ and $T_{w}$ may be iterated to determine if the $T_{w}$ calculated is near that of $T_{w}$ determined from average wall temperature values recorded by thermocouples. Once done $\mathrm{Q}$ can be calculated as follows and compared with the experimental values determined by the energy balances.

$$
Q=U * A * \Delta T_{l m}
$$

\section{Equipment and Procedures}

The DLMs, their use and instrumentation have been described in detail in other publications (ref. Paul's early ASEE paper and Baba's IJEE paper). Briefly, these units consist of a box slightly more than one cubic foot in total containing a small digital display, two single gallon reservoirs each connected to a $8.3 \mathrm{~W}$ centrifugal pump, rotameters, and thermocouples positioned at the inlet and outlet of exchangeable cartridges for measuring heat transfer in the cartridge, differential pressure readout, and optional recirculation system for a closed loop in each tank. A DLM is shown below in figure 1 with attached, unmodified shell and tube heat exchanger.

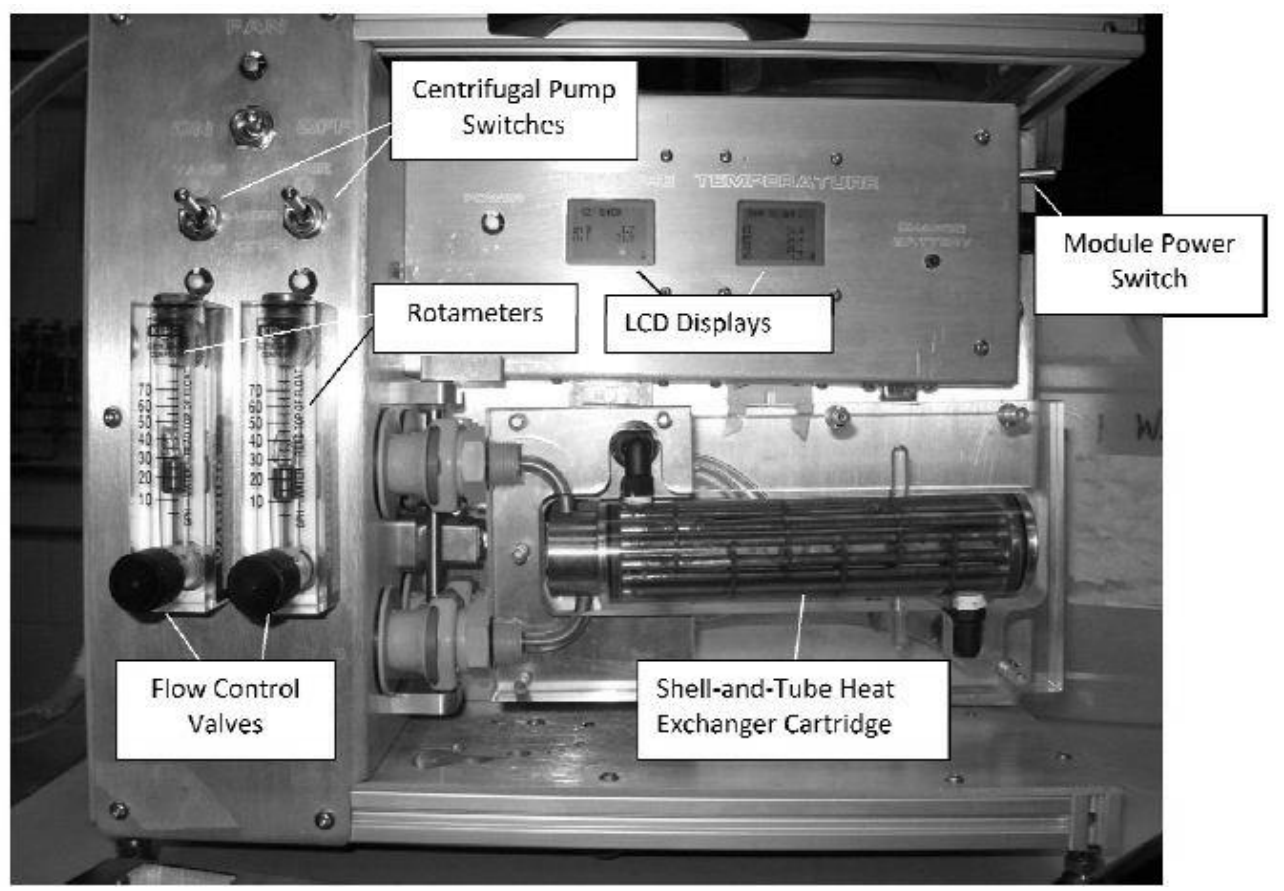

Figure 1 DLM frontal view with unmodified shell and tube cartridge ${ }^{14}$

In this analysis two cartridges are used, both shell and tube heat exchangers one of which has been modified with thermocouples placed at the shell side of the tube bundle wall at middle and wither ends on both first and second passes of the tube bank for a total of six thermocouples as shown in figure 2. A process flow diagram of the DLM with shell and tube cartridge can be seen below in figure 3. Our experiments for the present study were run on the DLMs using the 
standard attached pumps, rotameters, and temperature/pressure readouts for the main portion of the data gathered. Data gathered from the modified shell and tube was collected by handheld thermocouple readers. The data was used to analyze the validity of the application of heat transfer correlations developed for industrial sized equipment as applied to these miniaturized exchangers. By incorporating the optional recycle streams, connecting each reservoir line back to its appropriate reservoir, the data collected becomes connected dynamic data which can be easily filtered for extraneous data points. This method is used when collecting points every half second by hooking the DLM up to a computer program. By disconnecting the recycle streams from the tanks, the data is nearly static and collection by hand at 30 second intervals is possible producing data points that can be compared to each point before and after within a set rather than data only comparable between sets. This method is used when collecting data from the modified exchanger by hand held thermocouple readers.
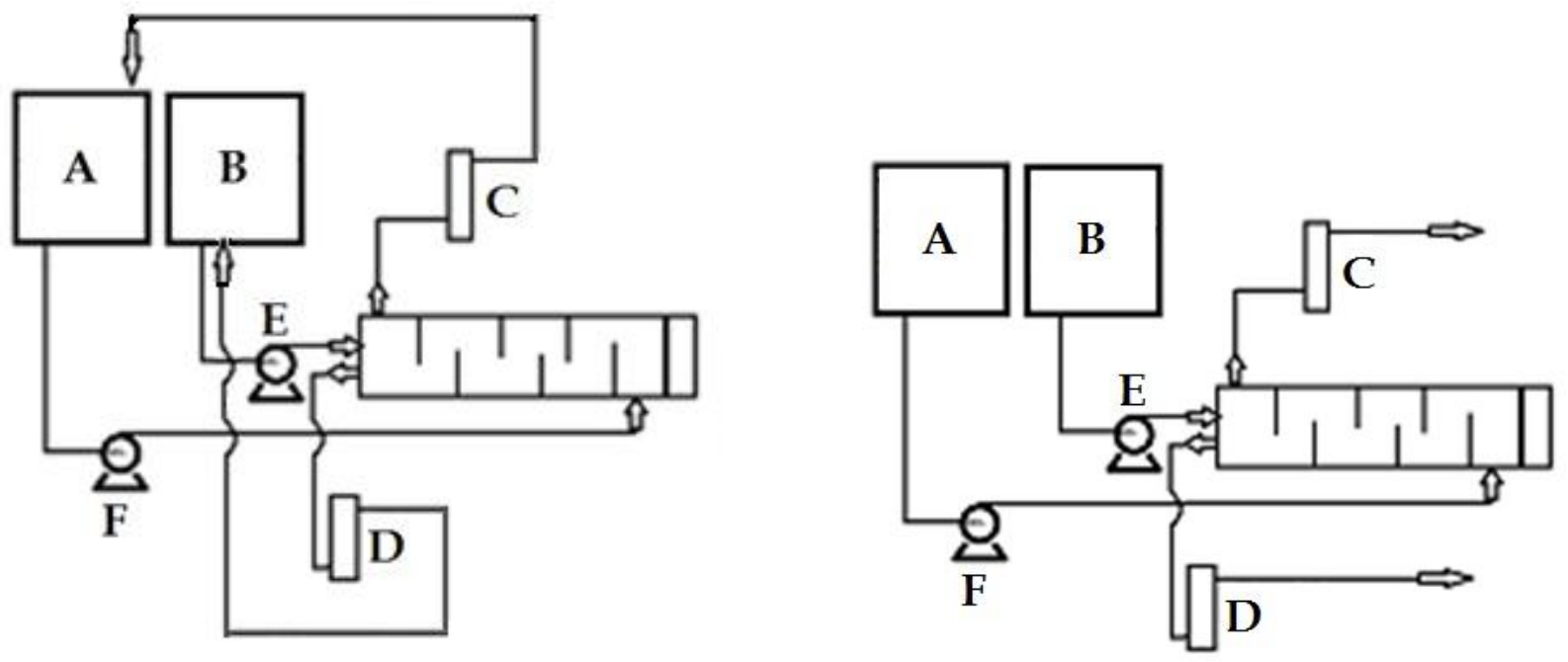

Figure 2: DLM Process Flow Diagram with attached Shell and Tube cartridge, A/B: reservoir tanks, C/D: rotameters for controlling flow, $\mathrm{E} / \mathrm{F}$ : centrifugal pumps Left: Configuration of unmodified cartridge experiments with recycle Right: Configuration of modified cartridge experiments with no recycle

Reservoirs in the experiments involving the modified exchanger were kept at steady temperatures and extended in volume by the addition of water from external sources at noted periods during data collection so the data sets could be elongated. 


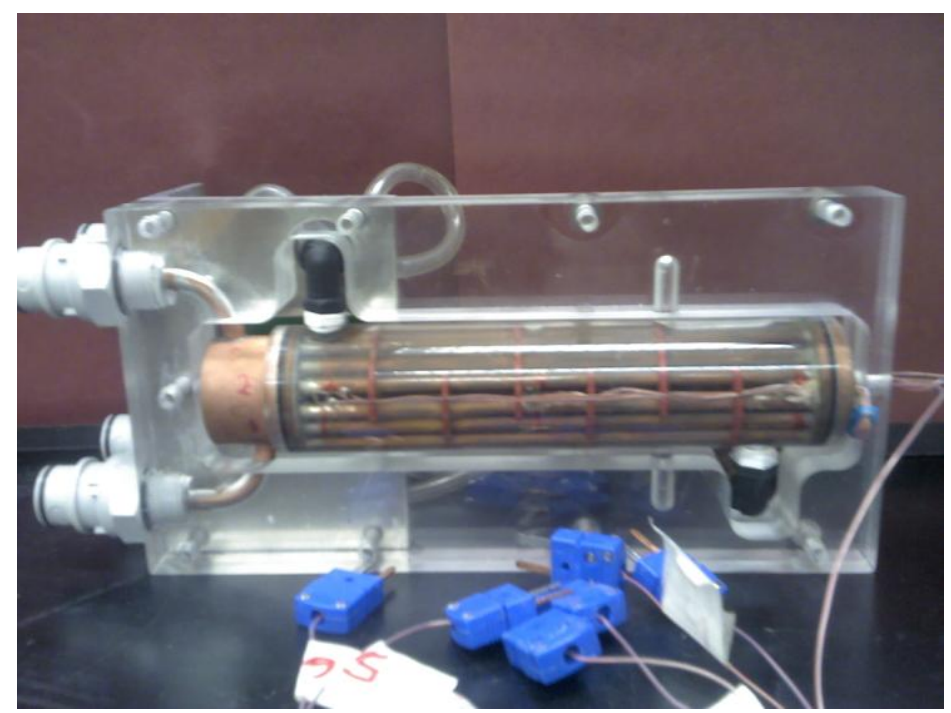

Figure 3 Modified Shell and Tube Cartridge with Wall Side Thermocouples

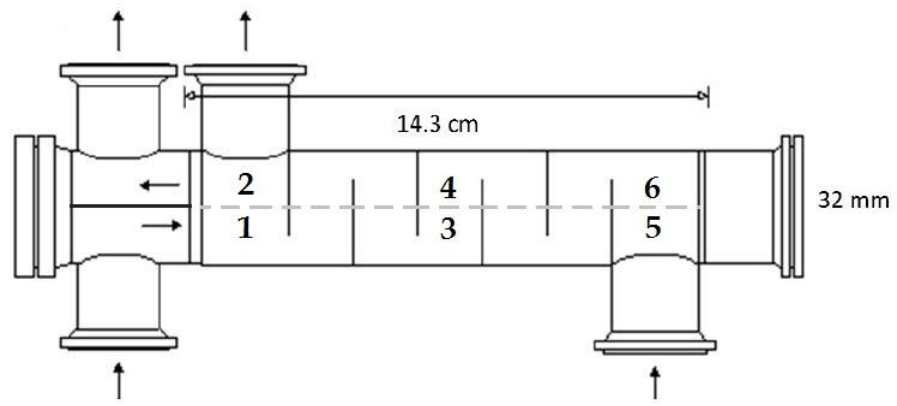

Figure 4 Modified cartridge thermocouple placement on shell side along tube bundle

The standard pumps on the DLM's give only very low flow rates and subsequently low Reynolds numbers on both tube side and shell side. Possible tube side flow rates are between 7 and 20 gallons per hour (GPH) at the outside, giving Reynolds numbers in the laminar regime (450900). Shell side flow rates have a larger range of flow rates, between 7 and 37 GPH consistently, but still put fluid flow in laminar Reynolds numbers (250-900). Trials for the modified shell and tube exchanger were all run with hot tube side fluid at $10 \mathrm{GPH}$ while varying the cold shell side between 10, 20, and 35 GPH. Trials for the unmodified shell and tube were run mostly with hot shell side at flow rate combinations of 10 and $20 \mathrm{GPH}$ on the tube side and 10, 15, 20, and 35 GPH on the shell side. All flow rate pairs are given in Table 1 and 2 in the results section along with the average percent errors on parameters $U_{i}, U_{o}, Q$, and including $h_{i}$ and $h_{o}$ for the modified exchanger data sets.

Before beginning to collect data, the DLM's are allowed to run for 15 minutes with room temperature water. Though the time to steady state is short; only a few seconds, the paper including this data is forthcoming; the pumps do not give their maximum possible flow rates until they have run for 10-15 minutes. Once this is done, the tanks are drained and filled with fresh water either hot or cold depending. For the unmodified trials, hot and cold tap water is used that starts at $40 \pm 5^{\circ} \mathrm{C}$ and $18 \pm 3^{\circ} \mathrm{C}$ respectively where the given range is between trials. The modified exchanger trials use more extreme temperatures by use of ice in the cold side reservoir 
and hot plate heating of external water sources on the hot side giving temperatures of $11 \pm 6^{\circ} \mathrm{C}$ and $82 \pm 10^{\circ} \mathrm{C}$ respectively where the range given is between the starting temperatures of different trials. Each trial runs 8-10 minutes, collecting four temperatures (in and out of each side) every half second digitally for the unmodified exchanger trials, and collecting eight temperatures of the 10 thermocouples (in and out on each side read from the built in digital display and 4 of the 6 read from hand held thermocouple readers) every 30 seconds by hand for the modified exchanger trials.

\section{Calibration}

After calibration and comparison with mercury thermometers $\left( \pm 0.05^{\circ} \mathrm{C}\right)$ the thermocouple readers were found to be precise to the $0.1^{\circ} \mathrm{C}$, but only accurate $\pm 2^{\circ} \mathrm{C}$ due to instrument noise during trials. The flow meters were calibrated with triple repetition data sets using a stopwatch and water collection measured by mass.

\section{Results and Discussion}

Though all flow rates possible by the standard DLMs give laminar flow regimes, negating the testing of transition or turbulent heat transfer correlations, the testing that can be done on laminar flow regimes over various temperatures and conditions proves to be quite effective. As previously hypothesized ${ }^{14}$ the DLM's shell and tube heat transfer cartridge performs to industry standards. As such, the correlations derived for industrial scale equipment is applicable to this miniaturized equipment under the same error associated with the correlations when applied to industrial scale equipment, $\pm 20-30 \%$ on both individual and overall heat transfer coefficients. Some trends have been found between the error on heat transfer coefficients and temperature difference between shell and tube side which is further discussed below along with a full analysis of results and tabulation of summarized data.

After analysis of data, the shell and tube cartridge for use in the DLM's were found to have large but acceptable errors on overall heat transfer correlations of $\pm 20-30 \%$ from experimentally determined heat transfer coefficients. This is exactly in accordance with the errors seen for a "fairly accurate estimate" as stated by Shah ${ }^{11}$. These errors are for experiments run with tap water reaching temperatures no higher than $120^{\circ} \mathrm{F}$ and no lower than $60^{\circ} \mathrm{F}$. When Experiments are run over a longer period of time with larger temperature extremes, high temperatures of $200^{\circ} \mathrm{F}$ and Lows of $38^{\circ} \mathrm{F}$, and the modified shell and tube, the error is roughly $5 \%$ larger than as discovered by the original cartridge and experimental setup including recycle.

By graphing the data, some trends in error present themselves. The percent error between correlated and experimental overall heat transfer coefficients in the DLM shell and tube exchangers appears to be a function of temperature difference between the shell and tube as well as flow rate and subsequently Reynolds number.

The first notable relation presents that error is inversely proportional to both shell side and tube side flow rate ergo Reynolds number. As exemplified in figure 5 for tube side flow rates below where the all odd data groups $\left(1^{\text {st }}, 3^{\text {rd }}\right.$, etc. $)$ have a lower tube side flow rate, $10 \mathrm{GPH}$, then the even data groups $\left(2^{\text {nd }}\right.$, $4^{\text {th }}$, etc.) which are at $20 \mathrm{GPH}$ tube side flow rate. The effect can also be seen in figure 6 as error decreases with inverse proportion to Reynolds numbers which is a function of flow rate. Tube side flow rate increase has a greater effect on percent error at roughly $10 \%$ decrease for a $10 \mathrm{GPH}$ increase in tube side flow as compared to the shell side effect of roughly $5 \%$ decrease in percent error for a $25 \mathrm{GPH}$ increase in flow. This is most likely a result of both rate of increased velocities and Reynolds numbers 
with relation to flow. As the tube side has a faster rate of increase for both velocity and Reynolds numbers with increase in flow, the effect of flow rate is seen more when applied to the tube side fluid.

The percent error also decreases with inverse proportion to shell and tube side temperature difference. The temperature effect can be seen when figures 5 and 7 are analyzed together. Here it is shown that percent error increases as time progresses and temperature difference between shell side and tube side fluids decreases. The data begins with a $29^{\circ} \mathrm{C}$ difference between shell and tube side inlet fluids at the left hand side of figure 7. As the data progresses, the percent error rises $10 \%$, concluding with a $15^{\circ} \mathrm{C}$ difference between shell and tube side fluids seen on the right side of figure 7.

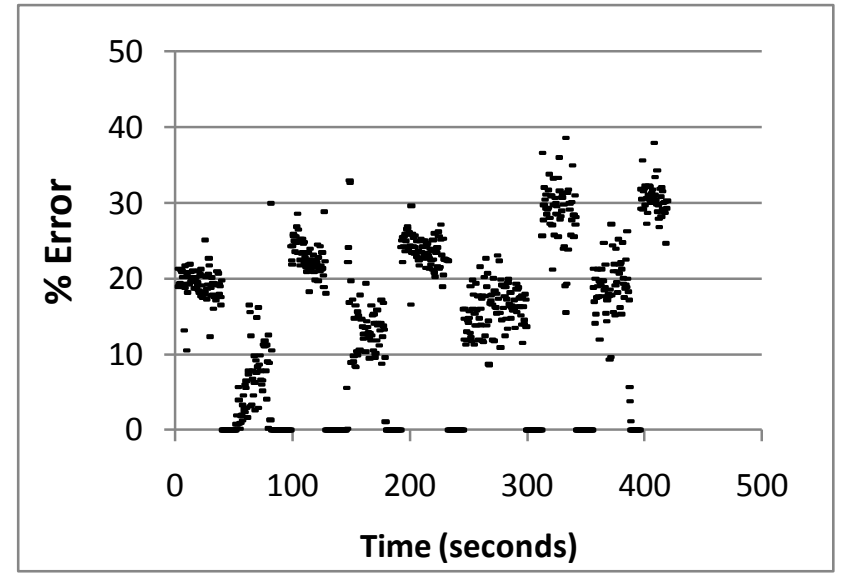

Figure 5 Percent Error on Overall Heat Transfer Coefficient Ui at Shell:Tube flow rates of 10:10 (Left) and 10:20 (Right) GPH in Relation to Tube Side Reynolds numbers

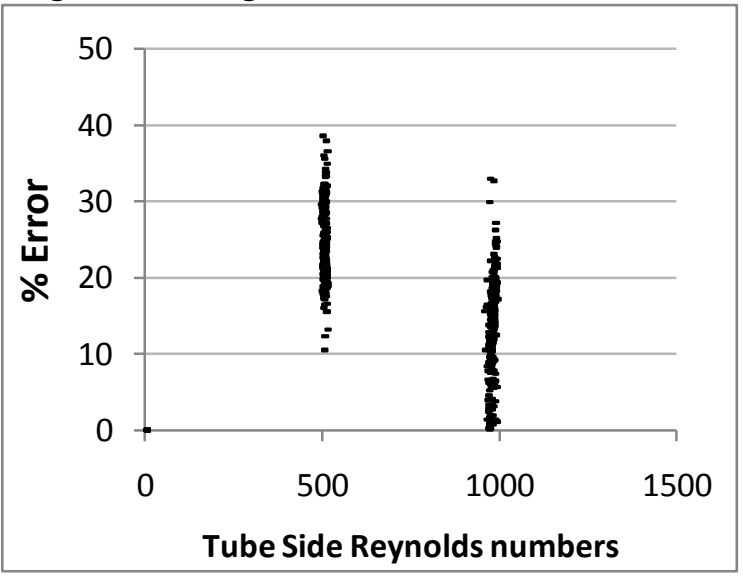

Figure 6 Percent Error on Overall Heat Transfer Coefficient Ui at Shell:Tube flow rates of 10:10 GPH (Odd numbered groupings) and 10:20 GPH (Even numbered groupings)

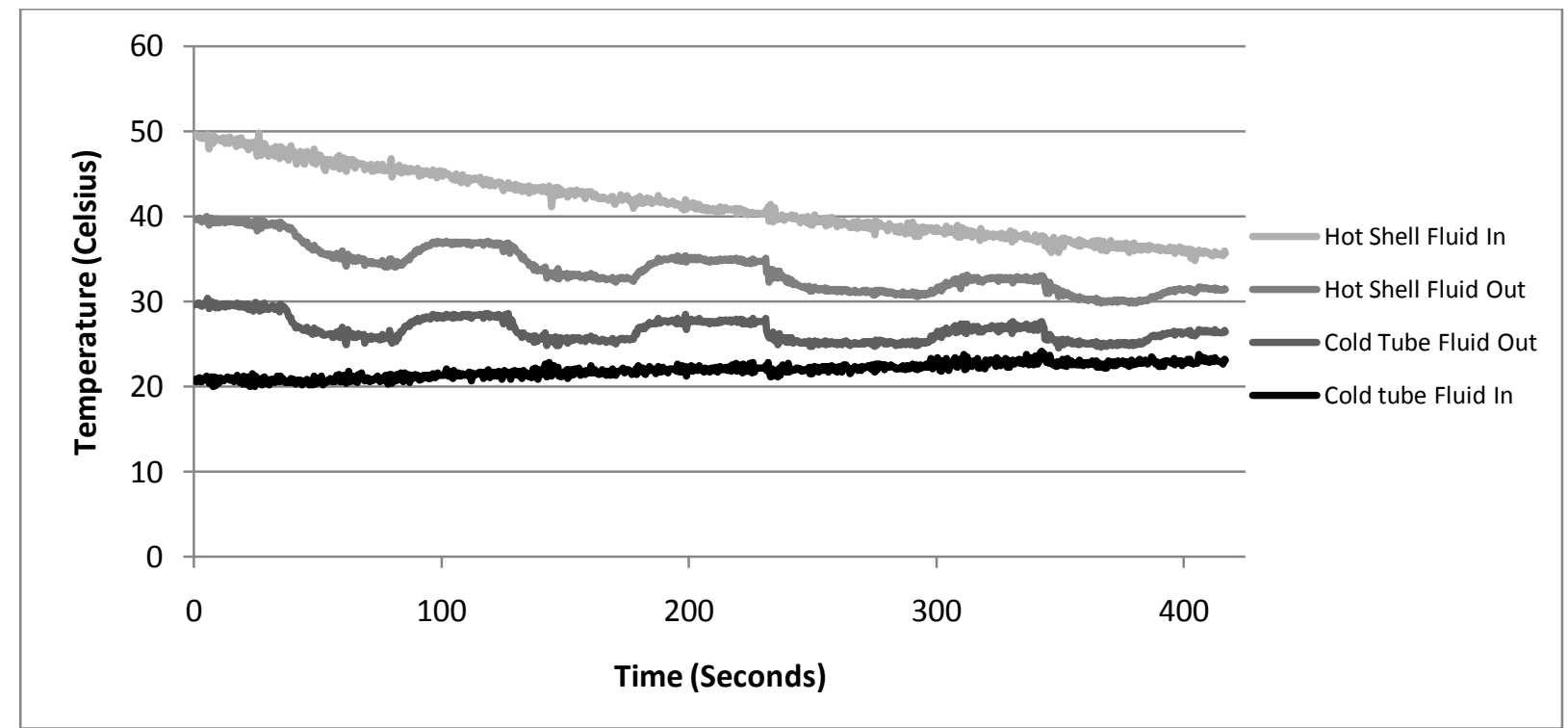

Figure 7 Time Vs Temperature data correlating with Figure $5 \& 6$ at Shell:Tube flow rates of 10:10 GPH (upper plateaus) and 10:20 GPH (lower plateaus) 
Table 1 data and analysis from unmodified shell and tube heat exchanger presented with a $95 \%$ confidence interval

\begin{tabular}{|c|c|c|c|c|c|c|c|c|c|c|c|c|}
\hline $\begin{array}{l}\text { Flow Rates } \\
\text { Shell:Tube GPH }\end{array}$ & $10: 10$ & \pm & $10: 20$ & \pm & $15: 15$ & \pm & $15: 20$ & \pm & 20:20 & \pm & $35: 10$ & \pm \\
\hline $\begin{array}{l}\text { Average \% Error } \\
\text { on Ui }\end{array}$ & 20.3 & 0.1 & 8.9 & 0.2 & 27.4 & 0.2 & 20.7 & 0.1 & 4.0 & 0.1 & 27.3 & 0.1 \\
\hline $\begin{array}{l}\text { Average \% Error } \\
\text { on Qi }\end{array}$ & 25.1 & 0.3 & 10.6 & 0.3 & 40.0 & 1.1 & 17.0 & 0.9 & 3.9 & 0.3 & 38.7 & 0.6 \\
\hline $\begin{array}{l}\text { Average hi } \\
\left(\mathrm{BTU} / \mathrm{ft}^{\wedge} 2 * \mathrm{hr} * \mathrm{~F}\right)\end{array}$ & 128.2 & 0.1 & 142.6 & 0.1 & 139.8 & 0.3 & 155.8 & 0.2 & 175.7 & 0.3 & 163.9 & 0.2 \\
\hline $\begin{array}{l}\text { Average ho } \\
\left(\text { BTU/ } \mathrm{ft}^{\wedge} 2 * \mathrm{hr} * \mathrm{~F}\right)\end{array}$ & 163.4 & 0.1 & 182.0 & 0.1 & 178.4 & 0.2 & 200.1 & 0.2 & 221.9 & 0.2 & 185.9 & 0.2 \\
\hline $\begin{array}{l}\text { Average Ui } \\
\left(\mathrm{BTU} / \mathrm{ft}^{\wedge} 2 * \mathrm{hr} * \mathrm{~F}\right)\end{array}$ & 80.4 & 0.1 & 89.5 & 0.1 & 87.8 & 0.2 & 98.0 & 0.1 & 109.8 & 0.1 & 103.0 & 0.1 \\
\hline
\end{tabular}

Table 2 data and analysis from modified shell and tube heat exchanger presented with a $95 \%$ confidence interval

\begin{tabular}{|l|c|c|c|c|c|c|}
\hline $\begin{array}{l}\text { Flow Rates } \\
\text { Shell:Tube }\end{array}$ & $\mathbf{1 0 : 1 0}$ & $\mathbf{\pm}$ & $\mathbf{2 0 : 1 0}$ & $\mathbf{\pm}$ & $\mathbf{3 5 : 1 0}$ & $\mathbf{\pm}$ \\
\hline $\begin{array}{l}\text { Average \% } \\
\text { Error on hi }\end{array}$ & 14.1 & 3.6 & 7.5 & 1.6 & 189 & 95 \\
\hline $\begin{array}{l}\text { Average \% } \\
\text { Error on ho }\end{array}$ & 314 & 89 & 270 & 78 & 150 & 53 \\
\hline $\begin{array}{l}\text { Average \% } \\
\text { Error on Ui }\end{array}$ & 33.7 & 2.4 & 35.8 & 1.5 & 31.6 & 2.5 \\
\hline $\begin{array}{l}\text { Average \% } \\
\text { Error on Uo }\end{array}$ & 36.4 & 3.9 & 23.5 & 3.7 & 52.2 & 13.5 \\
\hline $\begin{array}{l}\text { Average \% } \\
\text { Error on Qi }\end{array}$ & 53.3 & 5.7 & 56.7 & 3.6 & 47.6 & 4.7 \\
\hline $\begin{array}{l}\text { Average \% } \\
\text { Error on Qo }\end{array}$ & 68.1 & 11.6 & 24.9 & 3.6 & 36.3 & 6.2 \\
\hline & 119 & 1.5 & 130 & 1.3 & 137 & 1.5 \\
\hline Average hi & 165 & 1.4 & 184 & 1.4 & 194 & 1.7 \\
\hline $\begin{array}{l}\text { Average ho } \\
\text { Average Ui }\end{array}$ & 76.9 & 0.8 & 84.7 & 0.8 & 89.4 & 0.9 \\
\hline
\end{tabular}

Using the modified shell and tube cartridge exchanger (figure 2), data gathered by the excess thermocouples allows for the calculation and comparison of experimental to correlated individual heat transfer coefficients summarized in Table 2, and a view of the temperature profile within the exchanger shown in figure 4. 


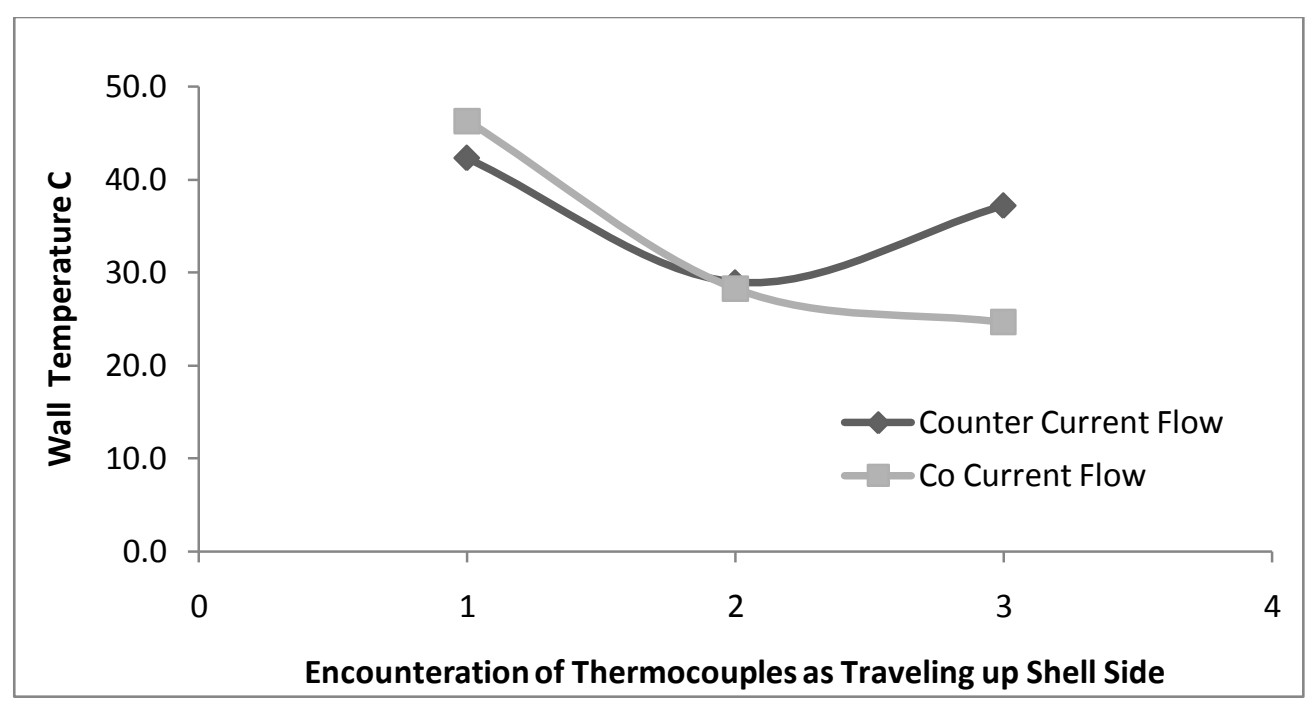

Figure 4 Counter and Co Current Temperature Profile within the Shell and Tube Heat Exchanger; Positions Corresponding to Thermocouples: 1=TC 1\&2; 2=TC 3\&4; 3=TC 5\&6; See figure 4 for physical thermocouple placement

The error on the outside individual heat transfer coefficient $h_{o}$ is expectedly ${ }^{12}$ high at 200-300 percent error. This is a product of using the Donahue equation at low Reynolds numbers and was, to an extent, expected ${ }^{12}$. The error on the inside individual heat transfer coefficient $h_{i}$ is a much more reasonable 15-20 percent error. Due to the consistently low Reynolds numbers produced by the DLMs, equations other than the Donahue equation for flow over baffled tube banks, need to be applied to model the outside individual heat transfer coefficient. Though the Donahue equation is one of the most common and easy to manipulate equations for modeling heat transfer on the shell side of a shell and tube heat exchanger, it is not the only one used in industry. This restriction in the abilities of the DLM shell and tube exchanger would benefit a Unit Operations Laboratory by exposing students to more than the ideal situation, which is also a more realistic situation.

Some of the thermocouple data from the modified shell and tube exchanger had to be filtered out due to a skewing effect. If the data had been kept in the analysis, the reported error for 35:10 GPH Shell:Tube flow rate would have been on the order of 1000 percent for the outside individual heat transfer coefficient. Given that the data filtered out was one set of thermocouple readings at one configuration, it would be fair to state that the best situation in which to use the modified shell and tube cartridge in the lab is when all of the thermocouples can be recorded at once, giving complete data points rather than pseudo complete data points as is the case when only four of the six wall side thermocouples may be recorded at one time. Though, even without this modification, it is possible to use the modified exchanger for experiments in the laboratory, allowing students to observe the temperature profile of a multi-pass shell and tube heat exchanger first hand.

Overall heat transfer coefficients (U) reside within the range of standard correlations, between 20 and 30 percent error. This amount of error on a correlated overall heat transfer coefficient, though seemingly large, still gives a "fairly accurate estimate" 11 and is exactly the standard of within reason. 


\section{Conclusions and Recommendations}

Overall the DLM shell and tube heat exchangers fall within correlation standards, $\pm 20-30 \%$ error on overall heat transfer coefficients, and would be a fine addition to the collection of any unit operations laboratory. Their low cost and modest footprint make them ideal for a low budget institution with little or no space to spare. As they run on batteries, and contain everything they need to be used aside from a hot and cold water source, the DLM's are ideal for even single classroom schools where there is no set area for a unit operations laboratory to be set up.

The DLM shell and tube heat exchanger behaves very similarly to an industrial scale exchanger. Deviations from mainstream industry lie in the restrictions to laminar flow, which is itself not unseen in industry and could prove a useful lesson or project for student groups to work around. These restrictions effect what equations must be used to model the system accurately for all parameters.

By creating a non ideal system, a real system so to say, students are taken out of the textbook and connected to the world where few things are ever ideal or without error. It is not so much learning to minimize the error, but rather knowing what is and is not acceptable, why errors arise from supposedly ideal systems and equations, and what should be or needs to be done about these errors. These are the valuable underlying lessons of nearly all life experience, and it is a deep seated goal that Unit Operations Laboratories hope to let their students loose on the world with this understanding.

No, the systems are not ideal, but that is exactly the point. The systems are however on par with industrial equipment and thus apt at teaching fluid flow and heat transfer concepts in relation to the real world. The DLM's give students the opportunity to learn the difference between ideal classroom problems, acceptable error that can be accounted for, and unacceptable error associated with systems that need to be designed or redesigned.

\section{Acknowledgements}

The authors wish to acknowledge the US National Science Foundation CCLI Grant (DUE$0618872 \&$ DUE-1023121), the staff and students of the Voiland School of Chemical and Bioengineering at WSU for support of the work to build, test and more importantly implement the DLMs. We also acknowledge the helpful contributions of Unit Operations Laboratory team mates, Chelsea Rosenkrance, Kelly Hultman and Scott Gray, for their assistance with determining experimental conditions, collecting data and producing this analysis. We acknowledge Derek Cline who collected data on temperature change with flow rate for the DLM Shell and Tube Cartridge. Finally, we acknowledge the important design contributions and manufacturing of the DLM from Mr. Gary Held, Machinist in the WSU College of Engineering and Architecture Machine Shop. 


\section{Nomenclature}

$\mathrm{A}_{\mathrm{i}} \quad$ Area of heat transfer calculated using the inside tube diameter

$\mathrm{A}_{\mathrm{o}} \quad$ Area of heat transfer calculated using the outside tube diameter

$\mathrm{Cp} \quad$ Heat capacity of fluid

$\mathrm{D}_{\mathrm{i}} \quad$ Inside diameter of the tubes

$\mathrm{D}_{\mathrm{L}} \quad$ Log mean diameter of the tubes

$D_{0} \quad$ Outside diameter of the tubes

$\mathrm{D}_{\mathrm{s}} \quad$ Inside diameter of the shell

$f_{b} \quad$ fraction of tube not covered by baffle (0.274)

$\mathrm{F}(\mathrm{G})$ Correction factor for $\Delta \mathrm{T}_{\mathrm{Im}}$ in multi pass heat exchangers

$\mathrm{Ge} \quad$ Mass velocity in shell $\left(\mathrm{lb} / \mathrm{ft}^{2} * \mathrm{hr}\right)$

Gr Grashof number $=\mathrm{D}^{3 *} \rho^{*}$ gravity* $\beta^{*} \Delta \mathrm{T}$ (outside wall to bulk fluid) ${ }^{*} \mu^{-2}$

$\mathrm{Gz} \quad$ Graetz number $=$ pi*Re*Pr*(D/L)/4

$\mathrm{k} \quad$ Thermal conductivity based on temperature

$\mathrm{k}_{\mathrm{w}} \quad$ Thermal conductivity of the copper tube wall

L Length of the shell, also length of one tube pass

m Volumetric flow rate

$\dot{\mathrm{m}}_{\mathrm{s}} \quad$ Shell side volumetric flow rate

$\dot{\mathrm{m}}_{\mathrm{t}} \quad$ Tube side volumetric flow rate

$\mathrm{N}_{\mathrm{b}} \quad$ Number of baffles

$\mathrm{N}_{\mathrm{t}} \quad$ Number of tubes per pass

$\mathrm{Nu}_{\mathrm{i}} \quad$ Nusselt number of the tube side

$\mathrm{Nu}_{0} \quad$ Nusselt number of the shell side

$\mathrm{P}_{\mathrm{b}} \quad$ Baffle pitch

Pr Prandtl number $=\mathrm{Cp}^{*} \mu / \mathrm{k}$

$\mathrm{P}_{\mathrm{t}} \quad$ Tube Pitch

$\mathrm{Q}_{\text {exp,i }}$ Experimental heat transfer rate to tubes

Qexp,o $_{\text {Experimental heat transfer rate to shell }}$

$\mathrm{Q}_{\mathrm{i}} \quad$ Correlated heat transfer rate to tubes

$\mathrm{Q}_{0} \quad$ Correlated heat transfer rate to shell

Re Reynolds number

$\mathrm{T}_{\text {bulk,o }}$ Bulk temperature of shell side fluid

$\mathrm{T}_{\text {bulk,i }}$ Bulk temperature of tube side fluid

$\mathrm{T}_{\text {cold, in }}$ Temperature of cold side stream entering

$\mathrm{T}_{\text {cold, out }}$ Temperature of cold side stream exiting

$\mathrm{T}_{\text {hot, in }}$ Temperature of hot side stream entering

$\mathrm{T}_{\text {hot, out }}$ Temperature of hot side exit stream

$\mathrm{T}_{\mathrm{in}, \mathrm{s}} \quad$ Shell side entering fluid temperature

$\mathrm{T}_{\mathrm{in}, \mathrm{t}}$ Tube side entering fluid temperature 
$\mathrm{T}_{\text {out, s }} \quad$ Shell side exit stream temperature

$\mathrm{T}_{\text {out }, \mathrm{t}}$ Tube side exit stream temperature

$\mathrm{T}_{\text {wall }}$ Temperature of fluid at the wall; neglecting temperature gradient over the wall due to thin, very heat conductive tubes $\left(1 / 8^{\text {th }}\right.$ inch thick copper), wall temperature is taken to be the same on both tube side and shell side.

$\mathrm{T}_{\text {wall,ave }}$ Arithmetic average wall temperature weighted for thermocouple placement. (Ex. If thermocouples at one end and the middle are used for the average of a single pass, the middle thermocouple is counted twice in place of a value for the missing thermocouple data)

$\Delta \mathrm{T}_{\operatorname{lm}} \quad$ Log mean temperature difference with correction factor

$\Delta \mathrm{T} \quad$ Temperature difference between average hot fluid temperature and average cold fluid temperature

$\mathrm{V}_{\mathrm{s}} \quad$ Shell side fluid velocity

$\mathrm{V}_{\mathrm{t}} \quad$ Tube side fluid velocity

$\mathrm{X}_{\mathrm{W}} \quad$ Tube wall thickness

Greek letters

$\beta \quad$ Thermal expansion coefficient

$\mu_{\mathrm{s}} \quad$ Average viscosity of the shell side fluid

$\mu_{\mathrm{t}} \quad$ Average viscosity of the tube side fluid

$\rho_{\mathrm{s}} \quad$ Average density of the shell side fluid

$\rho_{\mathrm{t}} \quad$ Average density of the tube side fluid

$\varphi \quad$ Viscosity correction factor 
Bibliography

1. Bjorklund, S.A., Parente, J.M., Sathianathan, D., 2004, "Effects of Faculty Interaction and Feedback on Gains in Student Skills," Journal of Engineering Education, Vol. 93, No. 2, pp. 153-160.

2. Colbeck, C.L., Campbell, S.E., Bjorklund, S.A., 2000, "Grouping in the Dark: What College Students Learn from Group Projects," Journal of Engineering Education, Vol. 71, No. 1, pp. 60-83.

3. Ellis, T., 2004, “Animating to Build Higher Cognitive Understanding: A Model for Studying Multimedia Effectiveness in Education," Journal of Engineering Education, Vol. 93, No. 1, pp. 59-64.

4. Grimson, J., 2002, "Re-engineering the Curriculum for the 21st Century," European Journal of Engineering Education, Vol. 27, No. 1, pp. 31-37.

5. Olinger, D.J., Hermanson, J.C., 2002, “Integrated Thermal-Fluid Experiments in WPI's Discovery Classroom,” Journal of Engineering Education, Vol. 91, No. 2, pp. 239-243.

6. Wise, M., Groom, F.M., 1996, "The Effects of Enriching Classroom Learning with the Systematic Employment of Multimedia" Education, Vol. 117, No. 1, pp. 61-69.

7. Golter, P.B., Van Wie B.J., Scuderi, P.V., Henderson, T.W., Dueben, T.M., Drown, G.R., Thomson, W.J., 2005, "Combining Modern Learning Pedagogies in Fluid Mechanics and Heat Transfer", Chemical Engineering Education, Vol. 39, No. 4, pp. 280-287.

8. Abdul, B., Shide, E., Bako, R., Golter, P., Babauta, J., Van Wie, B. and Brown, G., 2009, "An Evaluation of Pedagogical Gains in a Fluid Flow Class When Using Desktop Learning Modules in an African University," Proceedings of the 2009 American Society for Engineering Education Annual Conference and Exposition.

9. Beyenal, N., Poor, C., Golter, P., Brown, G., Thiessen, D. and Van Wie, B., 2009, “A Miniature Open Channel-Weir for the Standard Classroom: Implementation and Assessment, "Proceedings of the 2009 American Society for Engineering Education Annual Conference and Exposition.

10. Golter, P.B., Van Wie, B.J., 2007, "Desktop Learning Module Implementation”, Proceedings of the 2007 American Society for Engineering Education Annual Conference and Exposition

11. Shah, R.K., Sekulić, D.P., 2003, Fundamentals of Heat Exchanger Design, $2^{\text {nd }}$ edition, John Wiley \& Sons

12. McCabe, W. L., Smith, J.C., Harriott, P., 2005, Unit Operations of Chemical Engineering, $5^{\text {th }}$ edition, McGraw-Hill Book Company, New York.

13. Thomson, W.J., 2000, Introduction to Transport Phenomena, Prentice Hall, Inc., Upper Saddle River.

14. Paul, C.D., O’Neil, M.B, Penny, W.R., Van Wie, B.J., Golter, P.B., Beitle, R.R., Clausen, E.C., 2009 "Desktop Learning Module Heat Exchanger Performance" Proceedings of the 2009 Midwest Section Conference of the American Society for Engineering Education.

15. Perry, R.H, 1973, Perry's Chemical Engineers' Handbook, $5^{\text {th }}$ edition, McGraw-Hill Book Company, New York. 